\title{
Cyborg Rights
}

\author{
Roger Clarke \\ Xamax Consultancy Pty Ltd, Canberra and \\ Visiting Professor at U.N.S.W., Sydney and \\ the Australian National University, Canberra \\ Roger.Clarke@xamax.com.au
}

\begin{abstract}
The first generation of cyborgs is alive, well, walking among us, and even running. Pacemakers, renal dialysis machines and clumsy mechanical hands may not match the movie-image of cyborg enhancements, but they have been the leading wave. The legs of sprinter Oscar Pistorius, and implants of both the cochlear and RFID varieties, make more substantial changes to individuals. They also pose greater challenges to society as a whole.

Cyborgisation will give rise to demands for new rights. People who have lost capabilities but have not yet got the relevant prostheses will seek the right to have them. Some people will demand the right not just to recover what they are missing, but also to enhance themselves. Others will demand the liberty not to have prostheses imposed on them. Enhanced humans will seek additional rights to go with the additional capabilities that they have. The political processes involved in lobbying for and resisting these desires will take many and varied forms.

Professional engineers have an obligation to anticipate these developments, and to brief political, social and economic institutions on their nature, impact and implications. They have to date failed to do so. The rate of change is sufficiently brisk that action is urgent.
\end{abstract}

\section{Introduction}

Recent decades have seen an increasing incidence of interventions with the bodies of human beings. These interventions raise a variety of questions about rights. Some relate to the right to have the intervention performed, or not performed. Others involve the rights of people who have been the subject of an intervention.

The author addressed the question of 'human-artefact hybridisation' several years ago, in response to an invitation from the organisers of the Ars Electronica event in the Austrian city of Linz (Clarke 2005a). The purpose of the present paper is to build on brief comments made in s.5.2 of that presentation, and somewhat extended in brief companion papers (Clarke 2005b, 2005c), by conducting a deeper analysis of the rights aspects of human-artefact hybridisation.

The paper's scope is intentionally limited, in several ways. The motivation is instrumentalist not philosophical. The focus is on interventions of a physical, rather than of a biological or cognitive nature. The analysis is concerned with the functionality of the body, to the exclusion of merely cosmetic or ornamental interventions. It considers legal rights, not fundamental rights or moral rights. These limitations are further discussed in the Appendix.

The paper commences by defining the scope, investigating the concepts involved, and proposing a set of definitions to support the subsequent analysis. The notion of rights is briefly surveyed. The issues that arise are investigated by means of number of mini-cases. This enables the identification of 20 candidate rights. A discussion of alternative ways in which change may come about leads to conclusions about the responsibilities of the engineering profession.

\section{Cyborgisation}

This preliminary section discusses the notion of 'cyborg', commencing with its origins. Two forms of intervention with the human body are distinguished, which it is argued give rise to different implications. Key terms are defined, in order to provide a basis for the analysis that follows.

\subsection{Origins}

The term 'cybernetics' was coined by Norbert Wiener in 1948. It referred to the then-new notion of controlling human-designed processes through feedback and response, in ways similar to those evident in natural organisms (Wiener 1948, 1949). He contrived the word from the Greek word for 'steersman'.

The term 'cyborg' is a contraction of 'cybernetic organism', and entered the language in the early 1960s. Its origins are commonly attributed to two US research 
scientists, who used it to refer to an enhanced human being who could survive in extraterrestrial environments, or, in their own words "the exogenously extended organizational complex functioning as an integrated homeostatic system unconsciously" (Clynes \& Kline 1960).

More generally, a cyborg is a human with whom mechanical and/or electronic parts have been integrated. Driven by feature films that depict imaginings of sci-fi authors, popular culture envisages a cyborg as necessarily having functionality that has been extended beyond that of a normal human being. Indeed, the OED adopts that element of Clynes \& Kline (1960). Although one of its two definitions is "an integrated man-machine system", the other is "a person whose physical tolerances or capabilities are extended beyond normal human limitations by a machine or other external agency that modifies the body's functioning" (emphasis added). For the purposes of this analysis, however, it will be necessary to distinguish enhancements from more mundane, but nonetheless highly valuable interventions.

A related notion is 'bionic implants'. That concept is, however, largely confined to the entertainment arena, having originated in a 1973 novel called 'Cyborg', which gave rise to two television series called 'The Six Million Dollar Man' and 'The Bionic Woman' - each of whom had 'bionic' eyes, legs and arms. The OED's definition refers to "an artificial, esp. electromechanical, device that replaces part of the body; having ordinary human capabilities increased (as if) by the aid of such devices". It dates its use in this manner to the early-mid 1970s.

In popular culture, a cyborg's enhancements are physically inserted into the person. For the purposes of the analysis conducted in this paper, however, it is important to also encompass circumstances in which this condition is not satisfied. One important consideration is the need to include the notion of 'wearable computing'. This term has been in use since at least 1980, when Steve Mann applied it in particular to wearable cameras and head-mounted displays. More generally, see Rhodes (1997), and the product catalogue at Wearables Central. Reflecting this line of technological development, Mann proposed a broad definition of a cyborg as "a person whose physiological functioning is aided by or dependent upon a mechanical or electronic device" (Mann \& Niedzviecki 2001).

The formulation of an appropriate definition for 'cyborg' is deferred until after consideration of two different kinds of device.

\subsection{Prostheses}

The OED defines a prosthesis or prosthetic as "[a] replacement [for] defective or absent parts of the body [in the form of] artificial substitutes". Its traces its use in this manner to 1706. Drawing on the OED, Mann \& Niedzviecki (2001) and Clarke (2005a), this paper adopts the following definition for a prosthesis or prosthetic:

\section{an artefact that provides the human body with previously missing functionality or overcomes defective functionality}

In one sense, this definition is narrower than the OED, in that it requires the artefact to enable the performance of a function, and thereby excludes merely cosmetic or ornamental artefects such as glass eyes and breast implants.

On the other hand, this approach extends beyond the OED's 'new body-part' limitation to encompass the recovery of bodily function by means other than the installation of a substitute body-part. For example, a new and equivalent part could be added without removing the old one (as in renal dialysis); or a quite different part could be introduced (such as a heart pacemaker); or an existing body-part could be adapted by means of an artefact (such as a stent), without directly replacing the missing or defective one.

By avoiding any requirement that the artefact be installed inside the body, the definition opens up three sub-categories, reflecting different relationships between the prosthesis and the human body:

- Endo-Prosthesis. This is a prosthesis internal to the human body and satisfactorily interfaced with it. Examples include artificial hips and knees, stents, pacemakers, cochlear impants and implanted lenses

- Exo-Prosthesis. This is a prosthesis on an outer extremity of the human body and satisfactorily interfaced with it. Examples include contact lenses, and artificial hands, arms and legs

- External Prosthesis. This is a prosthesis separate from the human body, but satisfactorily interfaced with it. Examples include spectacles, walking sticks and crutches, but also renal dialysis and heart-lung machines

Common usages of the term 'prosthesis' focus on endoprostheses and to some extent exo-prostheses, but largely exclude external alternatives. The broader scope is necessary here, however, because the purpose is to examine the direction in which legal rights may need to be developed.

The OED defines prosthetics as "The design, manufacture, and fitting of artificial substitutes for missing or defective parts of the body; a branch of dentistry, surgery, or medical technology dealing with this", and traces its emergence to 1897. This paper uses the term more broadly, to refer to the technology of 
prostheses as a whole, whether they are substitutes or complements, and whether they are endo-, exo- or external.

\subsection{Orthoses}

The OED defines an orthosis or orthotic as "An external orthopaedic appliance or apparatus, such as a brace or splint, that serves to support, assist the function of, or prevent movement in a body part such as a limb or the spine". It traces its emergence to 1857 , but the usage is primarily from the mid-twentieth century. Used in that manner, its meaning overlaps with either or both of 'external prosthesis' and 'exo-prosthesis', as those terms were defined in the previous sub-section.

This paper adopts a rather different approach. Again following Mann \& Niedzviecki (2001) and Clarke (2005a), the following, more expansive definition of orthosis or orthotic is proposed:

\section{an artefact that supplements or extends a human's capabilities}

Whereas an artefact that assists in the recovery of normal sight is a prosthesis, one that provides 'sight' beyond the normal human-visible spectrum (e.g. infra-red detection) is an orthosis. Similarly, a replacement hand or leg may be a prosthesis if it recovers or replicates normal functions, or an orthosis if it extends them in some way. This approach therefore provides a term for a category of artefact that is quite different from prostheses, and that has significantly different implications. The FIDIS project drew the same distinction in relation to 'ICT implants', distinguishing those that "restore or repair human capabilities" - endo-prostheses, as the term is used in this paper, and those that "enhance ... human capabilities" endo-orthoses (FIDIS 2008b, pp.9-10, emphases in original).

The definition of orthosis enables a parallel set of terms to be applied, in order to distinguish the following sub-categories:

- Endo-Orthosis. This is an orthosis internal to the human body and satisfactorily interfaced with it. Examples include chip implants that disclose an identifier or other data, whether to assist the person's location to be found or tracked, or to, for example, automatically open a door

- Exo-Orthosis. This is an orthosis on an outer extremity of the human body and satisfactorily interfaced with it. Examples include artificial limbs that do something more than the natural limb would have done, such as extra fingers, highly-articulated joints, and spring-steel legs
- External Orthosis. This is an orthosis separate from the human body, but satisfactorily interfaced with it. Examples include telescopes and microscopes; skis, golf-clubs and snorkels; bodysuits such as those for knights, deep-sea divers, astronauts and competitive swimmers; and anklets and wristlets used to monitor the location of people such as prisoners, remandees, parolees and institutionalised patients

Orthotics is defined by the OED as "The branch of physiotherapy that deals with the use of orthoses; the design and fitting of orthoses", and is traced to 1957. It is used here more broadly, to refer to the technology of supplementary artefacts as a whole, and whether they are endo-, exo- or external.

\subsection{Prosthetes, Orthots and Cyborgs}

Terms are neede for the various categories of person arising from prosthetic and orthotic processes. The definitions adopted are as follows:

- Prosthete - a human with a prosthesis

- Orthot - a human enhanced by means of an orthosis

The definition adopted for cyborg reflects the preceding discussion, and draws particularly on the line of reasoning in Mann \& Niedzviecki (2001), which defined a cyborg as "a person whose physiological functioning is aided by or dependent upon a mechanical or electronic device" (emphases added), Clarke (2005a), and (FIDIS 2008). A cyborg is:

\section{a human with either or both of a prosthesis or an orthosis}

This approach differs from the OED definition of cyborg, which requires the person's capabilities to be "extended beyond normal human limitations", and hence is limited to people enhanced by what is called in this paper an orthosis. For the purpose of analysing cyborg rights, it is important to encompass both prosthetes and orthots.

The Clynes \& Kline (1960) notion of a cyborg also excluded prostheses, because it extended from an external orthosis (a space-suit) to exo- and endo-orthoses. In addition, their context of use was highly specific (extraterrestrial environments). Further, the orthosis needed to be substantially integrated with the human, so that it could be used unconsciously. This may be a desirable feature, but it is unnecessary to impose it as a definitional attribute.

Further terms are proposed, building on the above definitions. Prosthetisation, orthotisation and cyborgisation refer to the process of installing 
respectively a prosthesis, an orthosis, and either or both of them.

Further distinctions need to be drawn, to reflect the extent to which the person is an informed and willing subject, or the prosthesis or orthosis has been imposed on them:

- Voluntary Prosthetisation / Orthotisation / Cyborgisation. This arises where a person requests, or consents to, the prosthetic or orthotic process. The key characteristics of a valid consent are that it be informed and freely-given (Clarke 2002, EU 2005, FIDIS 2008b, p.37)

- Involuntary Prosthetisation / Orthotisation / Cyborgisation. This arises where the person does not consent to the prosthetic or orthotic process, but it is imposed upon them. Two further subcategories need to be distinguished:

- Overt, Involuntary Prosthetisation / Orthotisation / Cyborgisation. In this case, the person is aware of the imposition. An example is chip-enabled anklets for people in institutions (although not for dementia patients and the comatose, because they are incapable of providing informed consent)

- Covert, Involuntary Prosthetisation / Orthotisation / Cyborgisation. In this case, the person not only did not consent, but also is not aware that the process has been undertaken. An example is the close association of a tracking device to a person without it being brought to their attention, or otherwise coming to their attention

\section{Rights}

Human rights may be grounded in religion or philosophy. They may be abstract claims or interests, or they may be asserted to be fundamental, axiomatic and inalienable. This paper, however, is not considering philosophical notions or the justifications for laws, but rather laws themselves as they relate to prosthetes and orthots. The review undertaken is of necessity brief and superficial. All aspects of the topic are well-known, and hence little recourse is made to the formal literature. Otherwise unattributed quotations in this section are from relevant Wikipedia articles.

The term 'rights' is used in this paper in the sense of "legal, social, or moral freedoms to act or refrain from acting, or entitlements to be acted upon or not acted upon". In practical terms, the protection of a person's rights depends on:

- $\quad$ laws ("[systems] of rules, usually enforced through a set of institutions");

- $\quad$ the rule of law ("the law is above everyone and it applies to everyone"); and

- means whereby the relevant laws are actually enforced.

The history of legal authority for rights is long and tortuous. Commonly recognised steps along the way include Magna Carta (1215), the English Bill of Rights (1689), the French Declaration of the Rights of Man and of the Citizen (1789) and the U.S. Bill of Rights (17891791). In many countries, at least some rights are entrenched in the Constitution. Some rights, however, (and in some countries, all rights) depend on legislation that can be overturned by a mere Act of the Parliament, or (in common law jurisdictions) interpretations of case law by courts.

International codification of rights has been achieved, in the following primary forms:

- the Universal Declaration of Human Rights (UDHR 1948). UDHR is a 'declaration' not a 'treaty', and hence is not legally binding on countries. It is not without critics, particularly in the Muslim world. It has, however, influenced many national constitutions and treaties;

- the International Covenant on Civil and Political Rights (ICCPR 1966). Once acceded to, this is legally binding on countries (although enforcement is not easy). It is widely adopted, but with many reservations and declarations; and

- the International Covenant on Economic, Social and Cultural Rights (ICESCR 1966). This is perhaps less widely adopted, and is also subject to many reservations and declarations.

A useful distinction can be made between two categories of rights:

- $\quad$ a liberty right [is a right that entails only] a freedom or permission for the right-holder"; and

- $\quad$ a claim right is a right which entails responsibilities, duties, or obligations on other parties regarding the right-holder".

Rights may be declared in a positive manner, but they also arise as a corollary of obligations imposed on others. A relevant example of this is the widespread obligation on organisations to ensure that buildings that they occupy are accessible by people in wheelchairs. The obligation on the organisation implies a right of individuals who are 
dependent on wheelchairs for mobility to have convenient access to those buildings.

Another distinction of relevance to the analysis that this paper conducts is between three generations of rights:

(1) rights to liberty and participation in political life. Such rights are political in nature, and provide protections for the individual against excesses by the state. Examples include freedom of speech, the right to a fair trial, freedom of religion, and voting rights (addressed in UDHR Articles 3-21);

(2) rights to equality, which are social, economic, and cultural in nature. Examples include rights to be employed, to housing, to health care, and to social security and unemployment benefits (addressed in UDHR Articles 22-27); and

(3) further rights, which have to date achieved less broad international acceptance. Examples of potential relevance to this analysis include rights to self-determination, to economic and social development, to a healthy environment, to natural resources, to communicate, to participate in cultural heritage, and to intergenerational equity and sustainability.

An important aspect of rights is that they have been subject to adaptation over time. For example, until the nineteenth century, many commonly accepted rights applied to only some of the population. Even in 'modern, western democracies', a variety of those inequalities persisted well into the twentieth century, and some into the twenty-first. Developments during the late twentieth century have led to calls for additional rights to be recognised. For example, Internet-era rights were argued for even as the Internet was becoming widely available (Clarke 1995, Barlow 1996).

Rights are fragile. One example from the first decade of the new century is the substantial numbers of 'national security' over-rides of longstanding protections in 'free nations' that were justified by claiming that they are needed to thwart terrorist attacks. Another contrary trend is the resurgence of the collectivist perspective. In East Asia, this can be seen as a reaction against the western European tradition of humanism. Even within 'westernstyle democracies', however, some critics perceive the freedoms arising from human rights to be excessive or easily abused, and have argued for charters to emphasise responsibilities as well as rights. Concerns have also been expressed about the inherent dominance of the interests of the species homo sapiens over other animals and the plant kingdom, or over nature as a whole. The rise of environmentalism may result in further qualifications to human rights that have significant implications for resources, such as freedom of movement.
It is reasonable to expect that rights will continue to be subject to adaptation, and that new rights will emerge, and old rights will be modified, expanded and contracted. The purpose of this paper is to investigate adaptations that may be needed in order to deal with cyborgisation.

\section{Case Studies in Cyborgisation and Rights}

The literature reviews conducted during the preparation of this paper uncovered only a limited number of treatments of the specific topic. A sci-fi literature exists, which investigates many aspects of cyborgs, but primarily as threats to humankind. A techno-utopian literature considers cyborgs as posthumans, a philosophy literature considers moral and ethical aspects (although it focusses primarily on biological and cognitive enhancements rather than electro-mechanical artefacts), and there are derivative literary criticism and media studies literatures.

Few papers have been located, however, that adopt the instrumentalist perspective used in this paper, that examine cyborgs as they exist at present and appear likely to increasingly exist in the near future, and that consider rights as they apply to augmented human beings. Important exceptions include EU (2005) and FIDIS (2008b). See also the questions asked in the final paragraph of Warwick (2003) and in a use case scenario in FIDIS (2008a). Also relevant are the "ironic but serious proposal for a Cyborg Bill of Rights" in Gray (2001, p. 31), and the counter-argument in Levy (2003) to the effect that the challenges arising from cyborgisation are not radical.

In the absence of an established body of theory and evidence, the approach adopted in the present paper is to investigate dimensions of the issues through case studies of various cyborgs operating in various contexts. In order to ensure richness of material, the set intentionally includes a diversity of prostheses, of orthoses, and of contexts. The following section will summarise the evidence arising from the cases, in order to infer possible new forms of rights.

\subsection{Access to Quality-of-Life Prostheses}

The assistance of vision through the use of shaped glass dates back at least two thousand years, of lenses at least one thousand years, of spectacles at least 700 years, and of contact lenses 500 years in principle and 200 years in practice. An emergent right to have access to sightcorrective prostheses can be detected in health and welfare systems that provide them on a cost-less or heavily subsidised basis. A similar development path can be traced in relation to hearing-aids.

Particularly in the USA and the UK, military service personnel returning from war-zones have better access to opportunities for replacement limbs than, for example, 
victims of industrial and traffic accidents. A recent review of research work on neural control of artificial arms funded by the U.S. Defense Advanced Research Projects Agency (DARPA) is in Adee (2009). Another group that has superior access to expensive, new treatments is the aging rich. A ready justification for this is that the research and experimentation needed demands funding, and only the rich and the government can provide it.

By mid-century, it is conceivable that shoulder reconstructions, hip-joint replacements and knee replacements could have become a legitimate expectation for all who need them, rather than the expensive option for the war-maimed and the well-off and/or well-insured that they generally are at present.

\subsection{Access to Matter-of-Life-and-Death Prostheses}

Spectacles and hearing-aids recover impaired senses, and hence enhance quality of life. Even wheelchairs and replacement limbs can be argued to be facilities affecting quality-of-life rather than survival. A range of prostheses are likely to be associated not merely with improved quality of life but also increased life expectancy. Examples include stents, pacemakers, renal dialysis and artificial hearts and kidneys.

Debate can reasonably be anticipated as to whether patriotism and financial wealth should be such dominant factors in determining the priority of allocation of qualityof-life but especially matter-of-life-and-death prostheses.

A further issue arises where a person's survival is dependent upon one of the various categories of life support systems. When a person decides that their quality-of-life is too low, they may demand the right to disconnect from their external prosthesis, in full knowledge of the consequences. They may also demand the right to provide an enduring power of attorney or advance directive, instructing their next-of-kin and treatment professionals to disconnect the device under particular conditions (such as brain death).

\subsection{Cyborgs in Public Places}

Some sight-impaired people depend on guide dogs, and many mobility-impaired people depend on a walkingstick, or access to their own custom-designed wheelchair. In some jurisdictions, wheelchair access to public buildings has become a legal obligation, and hence effectively a right.

Contention has arisen where such external prostheses have been banned from premises, e.g. dogs, and specifically seeing-eye dogs, from restaurants, for health reasons. In some circumstances, a ban on the use of a personal wheelchair within particular premises - such as in an airport or on an aeroplane - may represent a denial of access to important services, and thereby harm the principle of equality of rights for the impaired. A variety of external prostheses create further challenges. For example, portable renal dialysis machines require both space and power.

Some endo-prostheses have already given rise to difficulties, such as pacemakers and artificial hips, which may be incompatible with airport security equipment. The prospect also exists of more direct security threats, such as hands made of steel (exo-orthoses) and implants that emit signals that could interfere with aircraft control systems (endo-orthoses).

\subsection{Exo- and Endo-Orthoses for Location and Tracking}

The use of anklets with embedded chips to facilitate detection of non-compliance with movement restrictions was first officially sanctioned in 1983, in New Mexico. Their use has spread to some other jurisdictions. They have been applied not only to prisoners, but to parolees as a condition of parole, and even to remandees (who have yet to be convicted of an offence, and may well never be). This represents an extension of the prison beyond the prison walls and reduces costs to the state. There is accordingly an incentive to extend their use to further categories, particularly recidivist criminals and detested (ex-?)criminals (e.g. those who have completed their sentences for child sex offences), but also dementia sufferers, comatose patients and perhaps other kinds of patients as well. Generally, an anklet is a form of overt involuntary exo-orthosis.

Chips have been implanted in livestock and pets since abut 1990. Chips have been offered for implantation in humans since about 1998, first in tooth-enamel and then in soft tissue. There have been a number of reported instances of chips being implanted in humans (Masters \& Michael 2006), although to date no reliable reference has been located for them being imposed involuntarily. A chip-implant is a form of endo-orthosis, and may be voluntary, overt involuntary, or even covert involuntary in nature 9Michael \& Michael 2009).

Like other endo-prostheses and endo-orthoses, the chip-implantation process may give rise to infection, it may be rejected by the body, and it may interfere with tissue, organs or bodily functions (CEJA-AMA 2007, Foster \& Jaeger 2007). The U.S. Food and Drug Administration (FDA) cleared the Verichip for implantation in 2004 (some years after it had first been implanted in humans). The decision was widely but misleadingly reported as being US government approval for the conduct of chip-implantation in humans.

\subsection{Handicapped Sports}


Many categories of handicapped sportspeople, particularly those participating in athletics and swimming, compete against others with similar disabilities and/or levels of disability. Commonly, the handicapped are protected from the prosthetes, and both the handicapped and prosthetes are protected from the able-bodied, e.g. by segregation into separate events or at least categories.

Wheelchair racers compete separately from the ablebodied as well. However, they go faster than runners. In the case of the New York Marathon, for example, the winner of the wheelchair event is about $35 \%$ faster than the winner of the foot-race. In such circumstances, segregation into separate events works the other way around, protecting the able-bodied from orthots. The able-bodied might be precluded from competing in wheelchair events. Alternatively, they might be permitted to compete, and they might even demand the right to do so.

A particular case of sports orthosis was drawn to attention in the presentation accompanying Clarke (2005a), in Hood (2005a and 2005b) and in some other media outlets around that time. Oscar Pistorius is a South African athlete, who competes in $200 \mathrm{~m}$ and $400 \mathrm{~m}$ events. In 2005, it was speculated that, if he continued his improvement, he would qualify for the 2008 Olympic Games, and by 2012 could be at least a semi-finalist. Oscar was born without lower legs, and has artificial legs that include carbon fibre blades.

The International Association of Athletics Federations (IAAF) determined that Pistorius' artificial legs "should be considered as technical aids which give him an advantage over other athletes not using them" (Robinson 2008). They accordingly banned him from competing against able-bodied athletes at the 2008 Olympics. This was based on an amendment to their rules, passed the previous year, that precludes use of "any technical device that incorporates springs, wheels or any other element that provides a user with an advantage over another athlete not using such a device", i.e. 'orthoses are banned'.

Pistorius challenged the ruling, and won, on the basis that the IAAF had failed to show that the legs gave him sufficient advantage (i.e. that the exo-prostheses were in fact exo-orthoses). Due to an injury-plagued preparation, however, he missed the qualifying standard by 0.70 seconds and did not satisfy the criteria for selection for his national team.

A media report has subsequently suggested that the IAAF may now have the required evidence (SD 2009), and hence may now succeed in banning double-amputees using such devices in able-bodied events. Ironically, the brand-name of the legs Pistorius uses is 'Cheetah' doubtless intended to imply speed, but perhaps now to be interpreted as an admission that they provide an unfair advantage to orthots over able-bodied athletes.

\subsection{Further Lessons from Professional Sport}

There are many ways in which sportspeople, and particularly professionals, seek advantages over their competitors. As a result, the administration of professional sport has been at the leading/bleeding edge of many issues arising from prostheses and orthoses. Exhibit 1 outlines some of the challenges confronted in recent years that may offer insights concerning where boundaries are judged to lie, and what kinds of rights are involved.

\section{Figure 1: Athlete Enhancement, Athletes' Rights}

- Performance-Enhancing Drugs. Issues that have arisen in this area include:

- the justification for the exclusion of a substance. Evidence is needed to support a determination that a substance is performance-enhancing in relation to each particular sport. This implies a right for people not to have their consumption preferences interfered with, unless there are grounds sufficient to justify the intrusion

- the exclusion of drugs with therapeutic effects. Issues have arisen in relation to commonly-used components of headache tablets and cough medicines, to pain-killers, and even to substances used to relieve common conditions such as asthma. This implies a right for people not to be denied treatment, particularly of significant medical conditions

- the specification of drug-testing regimes. This implies a right for people not to have their behaviour interfered with, not to have to declare their location, and not to have to notify their movements in advance, unless there are grounds sufficient to justify that level of intrusion

- the exclusion of sportspeople from competition. There is contention concerning the suspension of the right to compete while testing is incomplete, and concerning the denial of the right to compete following a finding of an infringement of drugconsumption rules, and even more so following a finding of an infringement of a condition of a drug-testing regime

- Performance-Enhancing Procedures. Many such procedures are permitted, including for example advance visits to the location of competition and 
altitude training. Some are proscribed, such as 'blood-doping'. This again implies a right for people not to have their behaviour interfered with, unless there are grounds sufficient to justify the intrusion

- Performance Recovery Procedures. Many such procedures are permitted, including for example hyperbaric chambers. This represents further evidence in support of a right for people not to have their behaviour interfered with, unless there are grounds sufficient to justify the intrusion

- Recreational Drugs. Some sports administrators embody in their terms compulsory testing for the consumption of substances that are not performanceenhancing, on grounds such as the potential for harm to the reputation of the sport. Some substances are permitted, such as alcohol; whereas others may be proscribed, and tested for, notwithstanding the fact that substance abuse is a criminal matter for law enforcement agencies to deal with rather than forprofit sports associations and corporations. This further implies a right for people not to have their behaviour interfered with, unless there are grounds sufficient to justify the intrusion

\subsection{An Emergent Chip-Bearing Norm?}

RFID chips respond to challenges from other devices, commonly making available to them a chip-identifier, and in some circumstances other data as well. Such chips are commonly 'promiscuous' in that they will respond to any demand for the data; but various security safeguards may be built in, to protect against various threats.

The passports issued by some countries now carry an RFID chip. Tollway payment cards are also commonplace - and most such applications have been designed in such a manner as to destroy the right to use roads anonymously. Public transport tickets, event tickets, and perhaps airport boarding passes, may be moving in the same direction. Some jurisdictions are seeking to add RFID chips to drivers' licences and, where they exist, to national id cards. Some consumer goods carry RFID chips through the distribution system from factory to retail outlet, and some of those may remain in the goods when they are purchased. Similar technologies can be used as a means of covert tracking of articles such as bags and cars, and hence as a means of covert tracking of the individuals who travel with them (Michael \& Michael 2005).

Items that carry an RFID-chip and that are closely associated with an individual represent a form of external or exo-orthosis. Individuals who have such chips implanted in them have an endo-orthosis. As discussed above, issues arise concerning knowledge and consent, and hence duress, sufficient cause, and due process.
It is possible that RFID chips may become a mainstream component of the way in which particular services are provided (e.g. the checking of passports and visas at border-crossings, entry to events, payment of tolls, payment of public transport fares). If so, then people who lack the orthosis may suffer disadvantages, and may even be denied some categories of service.

\subsection{Constraints on Cyborgisation}

People who develop or install some forms of prostheses, and particularly orthoses, may be subjected to opprobrium from some segments of the public. In some cases, this is 'luddite' behaviour, in the sense of a rejection of technology per se. Some opponents are opposed to particular artefacts rather than artefacts in general, because they perceive their use to be unnatural, 'playing God', against nature, or against human nature.

Orthoses may also be judged as violating principles and laws relating to human dignity, human inviolability, human autonomy and self-determination. An EU Opinion (i.e. without legal force) states that "access to ... implants for enhancement should be used only to bring [people] into the 'normal' range for the population, if they so wish and give their informed consent [i.e. as prostheses], or to improve health prospects (e.g. to enhance the immune system to be resistant to HIV) ... [and] implants used to enhance capabilities in order to dominate others [should be banned]" (EU 2005, p. 33, echoed in FIDIS 2008b, pp. 59-60) The first head approves of prostheses, but the second and third dis-approve of orthoses other than those that improve health prospects. Hence, for example, enhanced hearing, vision and motor skills would be precluded.

In some jurisdictions, all forms of artefact are subject to requirements of merchantable quality. Further, harm that arises from negligence may be subject to strict liability provisions. Endo- and exo-artefacts bring with them the risks of infection and rejection. Hence a concern for purveyors of prostheses and orthoses is that they may be held liable for malfunctions, contingent harm or sideeffects.

\subsection{Triumph of the Orthot?}

The notion of supremacism is concerned with the belief that some category of being is superior to or more worthy than others, and that the interests of that category should be the primary basis for value-judgements and decision-making. Some cultures have valued nature very highly, whether as a whole, or elements of it, such as mammals, or particular mammals such as primates, cetaceans and dogs. Many human societies, on the other hand, have been at least strongly anthropocentric and arguably anthropo-supremacist. The eugenics movement of the first half of the twentieth century aimed to develop 
more worthy humans, using biological interventions. It appears inevitable that some applications of cyborgisation by means of electro-mechanical artefacts will be whether subconsciously, tacitly, or expressly - intended to achieve much the same ends as eugenics.

The notion of techno-supremacism does not appear to have yet gained currency. Evidence for its emergence can be found, however, in the military, national security and law enforcement fields. For example, there has always been great difficulty in conducting prosecutions for acts performed in war-zones. Moreover, national military forces are commonly accused of ensuring that most acts taken against enemies, and many against local civilians, are effectively exempt from prosecution, particularly prosecution outside the military's own judicial system. Hence there is a sense in which national armed forces and their employees have rights that normal human beings do not.

Warfare is not only waged by armed forces raised and run by governments. Mercenaries have a long history, not least because of the profitability of the activity. In recent decades, mercenaries have achieved considerable public relations success, and shifted public perceptions, by means of new labels such as 'public military corporations' (PMCs). The services of PMCs include the supply of materiel, combat, intelligence-gathering and analysis, and the conduct of interrogations, including the use of torture.

The difficulty of conducting prosecutions for actions undertaken in war-zones applies to mercenaries/PMCs as it does to national military forces. There is also considerable evidence from recent wars in the Middle East that PMCs enjoy some degree of semi-formal legal shielding, much like government soldiers.

The implicit rights of human soldiers and mercenaries/PMCs to perform acts of violence without risk of legal retribution is relevant to this analysis because soldiers commonly use external orthoses in the form of weapons, and exo-orthoses such as protective suits. Further, there have been long-running projects to enhance soldiers, to improve both their effectiveness in neutralising the enemy and their capacity to survive attacks.

Civilian security personnel also have access to external orthoses such as batons, shields, radios and cameras, and to exo-orthoses such as protective suits. Where they can reasonably demonstrate the existence of danger or provocation, they may well argue for freedoms to act, of much the same kind as soldiers enjoy in battlefield contexts. A countermeasure against excesses by law enforcement agencies has emerged, in the form of 'sousveillance' (Mann et al. 2003). A form that sousveillance commonly takes is the augmentation of protestors and protest-observers with wearable cameras and video transmission capabilities (Mann 1997, 2009).
This cluster of mini-cases gives rise to at least two kinds of arguments in relation to cyborg rights. Firstly, the calls for more effective armoured protection for soldiers against Improvised Explosive Devices (IEDs) is evidence of an at least emergent right of a soldier to orthoses of a protective nature. Secondly, military and security orthots inherit what are effectively rights against prosecution, particularly for acts of violence in war-zones. Thirdly, because of their superior capabilities, military and security orthots may become leading-edge claimants for extended rights to exercise their extended powers. Finally, there are claims for a civil right to observe, transmit and record the behaviour of military and law enforcement forces.

\section{Implications}

This section draws on the cases outlined above in order to identify the kinds of rights that may be emergent, or may be at least asserted, claimed or desired, by various categories of people and organisations. It then examines ways in which such rights may come into existence.

\subsection{Candidate Rights}

The mini-cases described in the previous section identified in more or less precise form a set of 20 claims or interests that represent candidate rights. They are tabulated in Exhibit 2.

\section{Exhibit 2: Candidate Rights}

\section{Rights of the Non-Cyborg (or Pre-Cyborg)}

- a claim right on the state, to receive quality-of-life prostheses - case (1) - spectacles and hearing-aids

- a claim right on the state, to receive matter-of-lifeand-death prostheses - case (2) - renal dialysis, stents and pacemakers

- a liberty right to decline a prosthesis or orthosis case (4) - RFID-anklets and chip-implants, and case (7) - RFID chips as the norm

- a claim right on service-providers, to take due care in the design and testing of prostheses and orthoses and procedures for installing them - case (4) - chipimplantation

- a claim right on the organisers of sporting events, to enable participation in events with cyborg athletes case (5) - wheelchair sports

- a claim right on the organisers of sporting events, to enable participation in events separately from orthots - case (5) - double-amputees 
- a claim right on service-providers, preventing the denial of access to services by non-cyborgs - case (7) - RFID chips as the norm

- a claim right on employers, for orthoses of a protective nature - case (9) - IEDs

\section{Rights of the Prosthete}

- a liberty right to disconnect from a prosthesis - case (2) - life support systems

- a claim right on treatment professionals, to require disconnection from a prosthesis - case (2) - life support systems

- a claim right on operators of facilities, to be able to use external, exo- and endo-prostheses in facilities used by the public - case (3) - wheelchairs on aircraft

- a claim right on operators of security controls, to not be unduly discriminated against or subjected to demeaning procedures - case (3) - artifical hips

- a claim right on the organisers of sporting events, to enable participation in events separately from ablebodied athletes - case (5) - double-amputees

- a claim right on the organisers of sporting events, to enable participation in events with able-bodied athletes - case (5) - double-amputees

\section{Rights of the Orthot}

- a claim right on operators of security controls, to not be unduly discriminated against or subjected to demeaning procedures - case (3) - artifical hands

- a claim right on the organisers of sporting events, to enable participation in events with able-bodied athletes - case (5) - double-amputees

- a claim right against others, to be able to utilise their enhanced functional capability, perhaps only within a particular context, but perhaps generally, and at least in some circumstances free from retributive justice - case (9) - military and security personnel

- a liberty right, to be able to observe, transmit and record behaviour of others - case (9) sousveillance

\section{Rights of the Supplier and Installer}

- a liberty right to develop, experiment with and install prostheses and orthoses - case (8) constraints on cyborgisation
- a liberty right to be free from imposed legal liabilities except where negligence is demonstrated - case (8) - constraints on cyborgisation

\subsection{Processes to Facilitate Change}

If new balances are to be established in response to cyborgisation, then political triggers and processes are needed to bring about change. This sub-section considers some possibilities.

In common law jurisdictions, it is feasible for successive judgements by superior courts to accumulate a body of law that establishes new rights. The process is very slow and haphazard, however, and it offends politicians. Given the progress that has already been made with cyborgisation and the rapid rate at which it is developing, it would appear to be far more preferable to use law reform processes to achieve change.

Ethics and morality seldom have volitional or political force (Clarke 1999). On the other hand, claims for new rights can be usefully analysed from the perspective of applied ethics. An example of a field in which some progress has been made is bio-ethics, which has been active since at least the 1920s. Spurred on by Huxley's anti-utopian novel 'Brave New World', published in 1931, and the adoption of eugenics by the Nazi Party, the perception arose that biological sciences and bioengineering are meddling with human-ness, and that adjustments are needed to the framework within which relevant political, social and economic institutions operate. There has been significant feed-forward from the bio-ethics arena to law reform agencies and parliaments.

Like biologists, engineers have ethical obligations in relation to the impacts and implications of the new capabilities that they create. The basic tenet proposed in Clarke (1988) was that "all researchers and professionals must regard the implications of their work as part and parcel of their research in and application of IT. Consideration of implications needs to be integrated, not segregated".

Over two decades later, however, the IEEE Code of Ethics (version of 2006) still states merely that "[a member of IEEE commits] to accept responsibility in making decisions consistent with the safety, health and welfare of the public, and to disclose promptly factors that might endanger the public or the environment". This is completely vague about the implications for individuals, and nowhere is even this limited commitment translated into enforceable operational undertakings.

A fledgling robot ethics movement was initiated by Asimov (1942) as the Laws of Robotics, and examined in Clarke (1993) and FIDIS (2009). An IEEE Technical Committee on Roboethics has existed since 2004. But, 70 
years after the problem was defined, the movement appears to have generated no concrete outcomes.

Robotics has matured far more slowly than the imaginations of sci-fi authors and academic and commercial salesmen; so perhaps a 70-year delay in that particular endeavour represents no great problem for mankind. Cyborgs, on the other hand, are here and now. Indeed, fully 40 years ago, an outline of prosthetisation called 'The Cyborgs Among Us' had already been identified as one of many 'future shocks' (Toffler 1970, pp. 193-199). Despite that, virtually no progress has been made in professional self-regulation, still less in developing a formal regulatory regime. A contribution was located in the medical profession, but in the form of an internal Committee report with no direct impact (CEJA-AMA 2007). Contributions in the engineering profession are merely at the level of discursive articles such as Foster \& Jaeger (2007).

How are the questions of cyborg rights identified in this paper to be addressed in the absence of any regulatory framework? Of the most serious concern are involuntary orthosisation (under the pretence of choice, but without genuine consent) and covert orthosisation. Also of considerable concern are the right to disconnect, unfair discrimination, and the avoidance of unreasonable liability for harm arising from the installation and use of prosthetics and orthotics.

Exhibit 3 outlines, in concrete terms, functions that it is contended IEEE has a moral obligation perform.

\section{Exhibit 3: The Responsibilities of the Engineering Profession}

- The raising of public awareness, at national and international levels, about prosthetes, orthots and cyborgs generally, and the challenges that they give rise to

- The stimulation of discussion, at national and international levels, about prosthetes, orthots and cyborgs generally

- $\quad$ The informing of discussion about public policy issues arising from prosthetes, orthots and cyborgs generally

- Upgrades to professional Codes of Practice for those working on or with prosthetics and orthotics, initially expressed in abstract manner, but quickly moving to operational statements

- The expression of Conditions applying to the installation and use of particular kinds of artefact

- Upgrades to professional Codes of Practice and Membership Rules, in order to enable enforcement of the Codes and Conditions. In particular, it is necessary to:
- $\quad$ preclude membership by individuals who breach the Codes or Conditions, or are employed or contracted by corporations that do so

- $\quad$ preclude membership by, and stigmatise, corporations that work in breach of the Conditions, or that require or encourage their employees or contractors to breach the Codes or Conditions

\section{Conclusions}

The process of cyborgisation harbours great promise, but also significant threats. The scope for inequitable access to potentially beneficial prostheses is enormous, and so is the risk of a backlash against orthoses that are perceived to be 'unnatural' or potentially harmful. Political, social and economic institutions must grapple with the fruits of the labours of the information and communications technologies, and they must be informed by the professional bodies that represent the researchers and engineers. At present, however, those professional bodies are unacceptably inactive.

\section{Appendix: Scope Limitations of the Paper}

The purposes of this paper are limited and specific. The following scope limitations are drawn to attention.

1. The investigation is conducted in an instrumentalist rather than a philosophical context. It is concerned with contemporary and likely near-future realities, and appropriate responses to them. To the extent that practical implications are apparent to the author in the literatures of philosophy, fiction, literary criticism and media studies, they have been incorporated into the analysis; but no systematic review of those disciplines has been undertaken.

2. The paper emphatically does not indulge in speculative, techno-utopian discussion of the kinds prevalent in transhumanism (Bostrom 2005), posthumanism, mind-uploading and the singularity (a looming explosion of technological advancement that it is postulated will 'go critical' and usher in a vastly different culture later this century).

3. The focus is on interventions of a physical nature, primarily by means of electro-mechanical artefacts. The paper considers biological technologies only to the extent necessary to enable physical enhancements to be satisfactorily interfaced with the human body. It largely excludes consideration of cognitive extensions to human capabilities.

4. Interventions are encompassed that have an effect on the functionality of the body, rather than being merely cosmetic or ornamental, such as glass eyes, breast implants, body art and body modification for aesthetic 
reasons. However, some reservations are necessary about the wisdom of completely excluding artistic interventions in view of the cross-over that exists between art and functionality in the work of Stelarc.

5. The paper is concerned with rights afforded to individuals by the laws of the jurisdictions in which they live. It does not address the questions of 'fundamental rights', 'moral rights' or 'natural law'.

\section{References}

[1] Adee S. (2009) 'Winner: The Revolution Will Be Prosthetized ' IEEE Spectrum, November 2009, at http://spectrum.ieee.org/robotics/medical-robots/winnerthe-revolution-will-be-prosthetized/0

[2] Asimov I. (1942) 'Runaround', orig. published in 1942, in Asimov I. (1968) 'I, Robot' (a collection of short stories originally published between 1940 and 1950), Grafton Books, London, 1968, pp. 33- 51

[3] Barlow J.P. (1996) 'A Declaration of the Independence of Cyberspace' Electronic Frontiers Foundation, 8 February 1996, at https://projects.eff.org/ barlow/Declaration-Final.html

[4] Bostrom N. (2005) 'A History of Transhumanist Thought' Journal of Evolution and Technology 14, 1 (April 2005) 9-33

[5] CEJA-AMA (2007) 'Radio Frequency ID Devices in Humans' Report of the Council on Ethical and Judicial Affairs, CEJA Report 5-A-072007, American Medical Association, at http://www.amaassn.org/ama1/pub/upload/mm/467/ceja5a07.doc

[6] Clarke R. (1988) 'Economic, Legal and Social Implications of Information Technology' MIS Qtly 12,4 (December 1988) 517-9, at http://www.rogerclarke.com/DV/ELSIC.html

[7] Clarke R. (1993) 'Asimov's Laws of Robotics: Implications for Information Technology' IEEE Computer 26,12 (December 1993) pp.53-61 and 27,1 (January 1994), pp.57-66, at http://www.rogerclarke.com/SOS/Asimov.html

[8] Clarke R. (1995) 'Information Technology \& Cyberspace: Their Impact on Rights and Liberties' Xamax Consultancy Pty Ltd, September 1995, at http://www.rogerclarke.com/II/VicCCL.html

[9] Clarke R. (1999) 'Ethics and the Internet: The Cyberspace Behaviour of People, Communities and Organisations' Bus. \& Prof'l Ethics J. 18, 3\&4 (1999) 153-167, at http://www.rogerclarke.com/II/IEthics99.html [10] Clarke R. (2002) 'e-Consent: A Critical Element of Trust in e-Business' Proc. 15th Bled Electronic Commerce Conference, Bled, Slovenia, 17-19 June 2002, at http://www.rogerclarke.com/EC/eConsent.html
[11] Clarke R. (2005a) 'Human-Artefact Hybridisation: Forms and Consequences', Proc. Ars Electronica 2005 Symposium on Hybrid - Living in Paradox, Linz, Austria, 2-3 September 2005, version of May 2005, at http://www.rogerclarke.com/SOS/HAH0505.html

[12] Clarke R. (2005b) 'Human-Artefact Hybridisation and the Digital Persona', Xamax Consultancy Pty Ltd, May 2005, at http://www.rogerclarke.com/SOS/HAHDP0505.html

[13] Clarke R. (2005c) 'Hybridity - Elements of a Theory', Xamax Consultancy Pty Ltd, May 2005, at http://www.rogerclarke.com/SOS/HAHTh0505.html

[14] Clynes M.E. \& Kline N.S. (1960) 'Cyborgs and Space' Astronautics, September 1960, pp. 26-27 and 7475; reprinted in Gray, Mentor, and Figueroa-Sarriera, eds. 'The Cyborg Handbook' New York: Routledge, 1995, pp. 29-34

[15] EU (2005) ' Ethical Aspects of ICT Implants in the Human Body' Opinion of the European Group on Ethics in Science and New Technologies to the European Commission No. 20, 16 March 2005, at http://ec.europa.eu/european_group_ethics/docs/avis20_e n.pdf

[16] FIDIS (2008a) 'Use Case Scenario: Human enhancement, robots, and the fight for human rights' FIDIS Project, 2008, at

http://www.fidis.net/resources/use-cases-scenarios/humanenhancement-robots-and-the-fight-for-human-rights/

[17] FIDIS (2008b) 'A Study on ICT Implants' D12.6, Future of Identity in the Information Society, 30

September 2008, at http://www.fidis.net/fileadmin/fidis/deliverables/fidiswp12-del12.6.A_Study_on_ICT_Implants.pdf

[18] FIDIS (2009) 'Bridging the accountability gap: rights for new entities in the information society?' D17.3, Future of Identity in the Information Society, 28 April 2009, at http://www.fidis.net/fileadmin/fidis/deliverables/fidiswp17-del17.3-rights_for_new_entities_def.pdf

[19] Foster K.R. \& Jaeger J. (2007) 'RFID Inside' IEEE Spectrum, March 2007, at http://www.spectrum.ieee.org/mar07/4939

[20] Gray C.H. (2001) 'Cyborg Citizen' Routledge, 2001

[21] Hood M. (2005a) 'Running against the wind' IEEE Spectrum (June 2005), at http://spectrum.ieee.org/biomedical/bionics/runningagainst-the-wind

[22] Hood M. (2005b) 'Born to run' IEEE Spectrum (November 2005), at http://spectrum.ieee.org/biomedical/bionics/born-to-run/0 
[23] ICCPR (1966) 'International Covenant on Civil and Political Rights' United Nations, 16 December 1966, at http://www2.ohchr.org/english/law/ccpr.htm

[24] ICESCR (1966) 'International Covenant on Economic, Social and Cultural Rights' United Nations, 16 December 1966, at http://www2.ohchr.org/english/law/cescr.htm

[25] Levy N. (2003) 'Cyborgs-R-Us' Proc. ACM Int'l Conf. on Computers and Philosophy (eds. Weckert J. \& Al-Saggaf Y.), Vol. 37, 2003, pp. 13-17

[26] Mann S. (1997) 'An historical account of the 'WearComp' and 'WearCam' inventions developed for applications in 'Personal Imaging" Proc. ISWC, 13-14 October 1997, Cambridge, Massachusetts, pp. 66-73, at http://www.wearcam.org/historical/

[27] Mann S. (2009) 'Sousveillance: Wearable Computing and Citizen 'Undersight' - Watching from Below Rather Than Above' h+ Magazine, 10 July 2009, at

http://www.hplusmagazine.com/articles/politics/sousveilla nce-wearable-computing-and-citizen-undersight

[28] Mann S. \& Niedzviecki H. (2001) 'Cyborg: Digital Destiny and Human Possibility in the Age of the Wearable Computer' Random House, 2001

[29] Mann S., Nolan J. \& Wellman B. (2003)

'Sousveillance: Inventing and Using Wearable Computing Devices for Data Collection in Surveillance Environments' Surveillance \& Society 1, 3 (June 2003) 331-355, at http://www.surveillance-andsociety.org/articles1(3)/sousveillance.pdf

[30] Masters A. \& Michael K. (2006) 'Lend me your arms: the use and implications of humancentric RFID' Electronic Commerce Research and Applications 6,1 (2006) 29-39, at http://works.bepress.com/kmichael/40

[31] Michael M.G. \& Michael K. (2005) 'Microchipping people: the rise of the electrophorus' Quadrant XLiX, 3 (March 2005) 22-33, at

http://ro.uow.edu.au/cgi/viewcontent.cgi?article $=1373 \&$ co ntext=infopapers

[32] Michael M.G. \& Michael K. (2009) 'Uberveillance: Microchipping People and the Assault on Privacy' Quadrant LIII, 3 (March 2009) 85-89, at http://ro.uow.edu.au/cgi/viewcontent.cgi?article=1716\&co ntext=infopapers

[33] Rhodes B. (1997) 'A brief history of wearable computing' MIT Wearable Computing Project, apparently of 1997, at http://bradleyrhodes.com/Papers/brief-historyof-wearable-computing.html

[34] Robinson J. (2008) 'Amputee Ineligible for Olympic Events' The New York Times, 14 January 2008, at http://www.nytimes.com/2008/01/14/sports/othersports/14 cnd-pistorius.html?_r=1\&hp=\&pagewanted=print

[35] SD (2009) 'Oscar Pistorius' Artificial Limbs Give Him Clear, Major Advantage for Sprint Running, New Study Suggests' Science Daily, 18 November 2009, at 'http://www.sciencedaily.com/releases/2009/11/09111718 4539.htm

[36] Toffler A. (1970) 'Future Shock' Pan, 1970

[37] UDHR (1948) 'Universal Declaration of Human Rights' United Nations, 10 December 1948, at http://www.un.org/en/documents/udhr/index.shtml

[38] Warwick K. (2003) 'Cyborg morals, cyborg values, cyborg ethics' Ethics and Information Technology 5, 3 (September 2003) 131-137

[39] Wiener N. (1948) 'Cybernetics, or Control and Communication in the Animal and the Machine' MIT Press, Cambridge, Massachusetts, 1948, 1961 [40] Wiener N. (1949) 'The Human Use of Human Beings' Avon Books, New York, 1949, 1974

[40] Wiener N. (1949) 'The Human Use of Human Beings' Avon Books, New York, 1949, 1974

\section{Glossary}

Covert ..

Of Involuntary Prosthetisation, Orthotisation or Cyborgisation, where the person is not aware of the prosthetic and/or orthotic (2.4)

Cyborg A human with either or both of a Prosthesis or an Orthosis (2.4)

Cyborgisation The process of installing either or both of a Prosthesis or an Orthosis (2.4)

Endo-Orthosis An Orthosis internal to the human body and satisfactorily interfaced with it (2.3)

Endo-Prosthesis A Prosthesis internal to the human body and satisfactorily interfaced with it (2.2)

Exo-Orthosis

An Orthosis on an outer extremity of the human body and satisfactorily interfaced with it (2.3)

Exo-Prosthesis A Prosthesis on an outer extremity of the human body and satisfactorily interfaced with it (2.2)

External Orthosis An Orthosis separate from the human body, but satisfactorily interfaced with it (2.3) 
External Prosthesis A Prosthesis separate from the human body, but satisfactorily interfaced with it (2.2)

Involuntary ... $\quad$ Of Prosthetisation, Orthotisation or Cyborgisation, neither at the person's request, nor with the person's consent (2.4)

Orthosis (also n. Orthotic)

An artefact that supplements or extends a human's capabilities (2.3)

Orthot A human enhanced by means of an Orthosis (2.4)

Orthotics The technology of Orthoses (2.3)

Orthotisation The process of installing an Orthosis (2.4)

Overt ...

Of Involuntary Prosthetisation, Orthotisation or Cyborgisation, where the person is aware of the prosthetic and/or orthotic (2.4)

Prosthesis (also n. Prosthetic)

An artefact that provides the human body with previously missing funcitonality or overcomes defective functionality (2.2)

Prosthete

A human with a Prosthesis (2.4)

Prosthetics

The technology of Prostheses (2.2)

Prosthetisation

The process of installing a Prosthesis (2.4)

Voluntary ...

Of Prosthetisation, Orthotisation or Cyborgisation, at the person's request, or with the person's consent (2.4) 